\title{
A transthyretin variant (alanine 49) associated with familial amyloidotic polyneuropathy in a French family
}

\author{
M D Benson II, J Julien, J Liepnieks, S Zeldenrust, M D Benson
}

\begin{abstract}
A transthyretin mutation was discovered in a French family with familial amyloidotic polyneuropathy originally described in 1983. The syndrome is of early onset (approximate age 35 to 40) with carpal tunnel syndrome. Death is from cardiac disease. By direct genomic DNA sequencing an $A \rightarrow G$ mutation was found in the position corresponding to the first base of transthyretin codon 49 . The predicted alanine for threonine substitution in the transthyretin protein was proven by amino acid sequencing of transthyretin isolated from the plasma of an affected subject. Since the DNA mutation does not result in the creation or abolition of a restriction endonuclease recognition site, a new DNA analysis technique was used in which site directed mutagenesis is used to create an RFLP when the introduced mutation is in proximity to the natural mutation. Using a 27 nucleotide mutagenesis primer in the PCR reaction, a new Bg1I site was created on amplification of the variant allele. Using this test, termed PCR-IMRA, four affected members of the family were shown to have the mutation.
\end{abstract}

(f Med Genet 1993;30:117-19)

Mutations in the gene for plasma transthyretin (prealbumin) are the most common cause of familial amyloidotic polyneuropathy (FAP). ${ }^{1}$ Since the first disease associated mutation in transthyretin was discovered in 1983, over 20 other mutations have been found associated with FAP. While the FAP syndromes are similar, having varying degrees of neuropathy,

\section{Materials and methods}

A rectal biopsy was obtained from one member of this kindred. Paraffin embedded sections were stained with anti-transthyretin as previously described. ${ }^{3}$ Transthyretin was isolated from the plasma of one family member using a three stage chromatography procedure as previously described. ${ }^{4}$ Isolated transthyretin was digested with trypsin and the tryptic peptides separated by HPLC. Amino acid sequencing was carried out on a Beckman $890 \mathrm{C}$ sequenator with the dilute quadrol program. DNA was isolated from five members of the family as previously described. ${ }^{5}$ Approximately $1 \mu \mathrm{g}$ genomic DNA was amplified using the polymerase chain reaction (PCR) and one of three sets of primers flanking TTR gene regions containing either exon 2,3 , or $4 .^{6}$ Thirty cycles of amplification consisted of denaturing at $94^{\circ} \mathrm{C}$ for one minute, annealing at $65^{\circ} \mathrm{C}$ for one minute, and extending at $72^{\circ} \mathrm{C}$ for one minute.

Pessac, France.

J Julien

Richard L Roudebush

Veterans Affairs

Medical Center,

Indianapolis, Indiana,

USA.

J Liepnieks

M D Benson

Indiana University

School of Medicine,

Department of

Medical and

Molecular Genetics,

Indianapolis, Indiana,

USA.

$S$ Zeldenrust

M D Benson

Correspondence to

Professor Benson.

Received 2 May 1992.

Revised version accepted

23 July 1992.

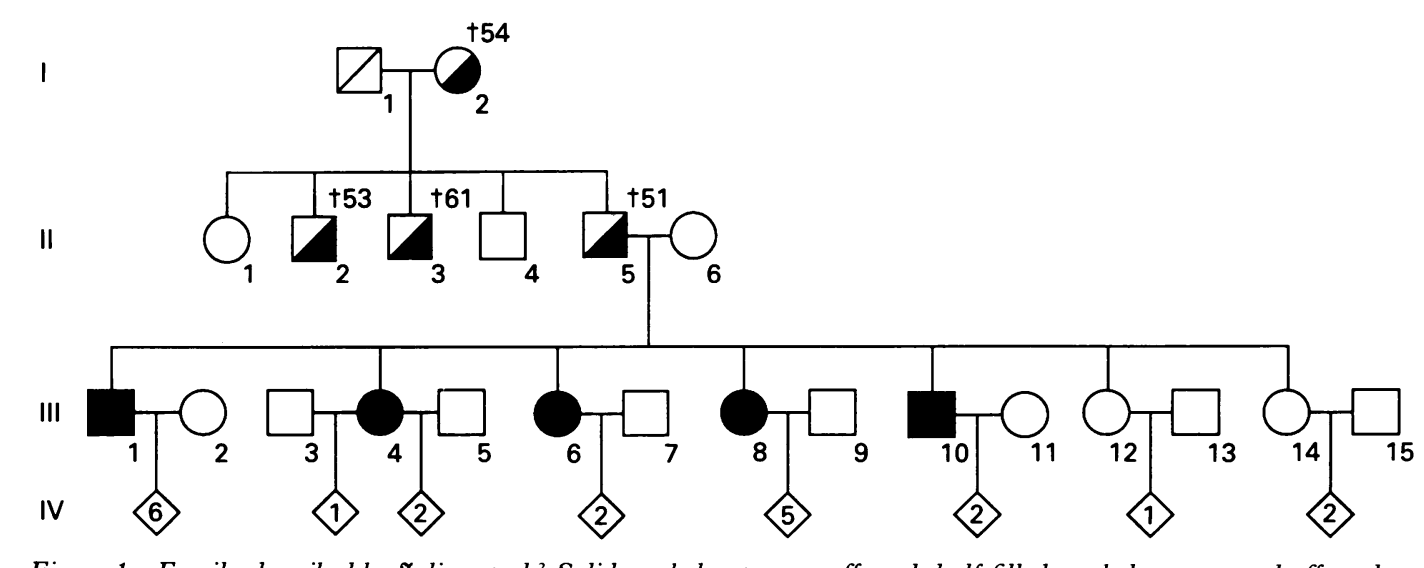

Figure 1 Family described by fulien et al. ${ }^{2}$ Solid symbols=proven affected, half filled symbols $=$ presumed affected. $I \cdot 2$ died aged 54 years. 
Amplification products were separated on $4 \%$ composite agarose gels (3\% FMC NuSieve/ $1 \%$ Bethesda Research Labs). A pasteur pipette was used to remove a plug of agarose containing a portion of the amplification product. The agarose plug was melted at $75^{\circ} \mathrm{C}$ for 15 minutes in $1 \mathrm{ml}$ of $10 \mathrm{mmol} / 1$ Tris $\mathrm{pH} 8.0,1 \mathrm{mmol} / 1$ EDTA. Single stranded templates for direct sequencing were generated using 40 pmol PCR primer 2, 0.8 pmol PCR primer 1 , and $1 \mu \mathrm{l}$ of the $1 \mathrm{ml}$ agarose extracted samples. ${ }^{7}$ Forty cycles of amplification were performed; first step $94^{\circ} \mathrm{C}$ for one minute, second step $65^{\circ} \mathrm{C}$ for one minute, third step $72^{\circ} \mathrm{C}$ for one minute. Samples were extracted with phenol and chloroform and subjected to spin dialysis using centricon 30 microconcentrators. Sequencing of single stranded templates was performed using $7 \mu 1$ of each retentate mixed with $1 \mu \mathrm{l}$ of a $5 \mathrm{mmol} / \mathrm{l}$ solution of PCR primer 1 and $2 \mathrm{ml} 5 \times$ reaction buffer (sequenase version 2.0, US Biochemicals). Labelled reactions were electrophoresed for two hours at 60 watts, dried overnight, and exposed to Kodak X-omat film for 48 hours at $-70^{\circ} \mathrm{C}$.

\section{PCR-IMRA}

Since the adenine to guanine transition identified in this family does not create an RFLP, an alternative testing method was devised, based on a variation of directed mutagenesis using the polymerase chain reaction, which we have termed polymerase chain reaction-induced mutation restriction analysis (PCR-IMRA), and was used to analyse genomic DNA for the TTR exon 3 mutation. ${ }^{8}$ To create an RFLP for this mutation a 27 nucleotide mutagenesis primer was synthesised. This primer (A49 PCR-IMRA, fig 2) was designed to anneal immediately $3^{\prime}$ to the site of the mutation and contains a single mismatch near its $3^{\prime}$ end. When used in the PCR amplification of TTR exon 3, a new $B g l \mathrm{I}$ site is created when the amyloid associated $A \rightarrow G$ transition is present. Amplification was performed on $1 \mu \mathrm{g}$ genomic DNA, using $150 \mathrm{ng}$ each of primers A49 PCRIMRA and E3LP1. ${ }^{6}$ Thirty-five cycles of amplification were performed; first step $94^{\circ} \mathrm{C}$ for one minute, second step $65^{\circ} \mathrm{C}$ for one minute, third step $72^{\circ} \mathrm{C}$ for one minute. Completed reactions were extracted with chloroform and a $10 \mu \mathrm{l}$ aliquot electrophoresed on $4 \%$ composite $(3 \%$ NuSieve, $1 \%$ BRL) agarose gels to determine success of amplification. An additional $10 \mu \mathrm{l}$ aliquot was digested with $10 \mathrm{U} B g l \mathrm{I}$ according to the manufacturer's specifications. The entire digestions were electrophoresed on $4 \%$ composite agarose gels, stained with ethidium bromide, and visualised by UV light.

\section{Results}

Immunohistochemistry with anti-transthyretin stained vascular amyloid deposits in a rectal biopsy from one affected member of the family confirming that this was an inherited transthyretin amyloidosis.

Direct DNA sequencing of genomic DNA from an affected subject (III $\cdot 1$ ) showed the presence of both the normal adenine and a guanine in the position corresponding to the first base of codon 49 in transthyretin exon 3 (fig 3). No other mutation was found in exons 2,3 , or 4 . This mutation predicts an alanine for threonine substitution in the transthyretin protein. Tryptic digestion of plasma transthyretin from a member of this family produced a new tryptic peptide on HPLC. Sequencing of this tryptic peptide $\left(\mathrm{T} 7^{*}\right)$ showed an alanine amino-terminal residue instead of the normal threonine. Normal T7 was also isolated from this digestion and shown by sequence analysis to have threonine as the amino-terminal residue.

Since the substitution of $G$ for A does not result in the creation or abolition of a restriction endonuclease recognition site, PCRIMRA was used to generate an RFLP. A 27 nucleotide mutagenesis primer was used in the PCR reaction to create amplification products. In this PCR reaction, an $88 \mathrm{bp}$ PCR product is generated from both the normal and variant alleles (fig 4). After digestion with $B g l \mathrm{I}$, the variant PCR product is cut into two fragments ( $62 \mathrm{bp}$ and $22 \mathrm{bp}$ ). In the heterozygous state, both the $88 \mathrm{bp}$ undigested product of the normal allele and the $62 \mathrm{bp}$ digestion product of the variant allele can be visualised on agarose electrophoresis. Genomic DNA samples from four affected members of this kindred were analysed by PCR-IMRA and all showed heterozygosity for the $A \rightarrow G$ mutation. An unaffected cousin (not shown on the pedigree) was negative for this mutation.

\section{Discussion}

This French family with FAP was originally the subject of study because of clinical similarity to the FAP type II syndrome of the Indiana/Swiss kindred. ${ }^{9}$ Testing for the serine 84 TTR mutation of the Indiana/Swiss kindred was negative, however, as were tests for other known mutations (methionine 30, isoleucine 33 , histidine 58 , alanine 60 , tyrosine 77 , methionine 111 , isoleucine 122 , arginine 26, and apolipoprotein A1). After immunohistochemistry showed transthyretin in vascular deposits of a rectal biopsy from one member of the kindred, it was postulated that this syndrome could be associated with a different mutation. The first evidence that a new mutation was involved was found by sequence

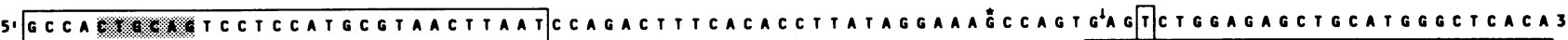

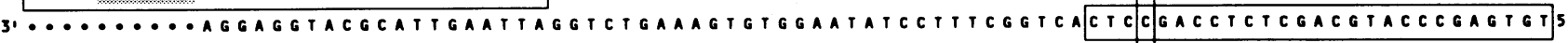




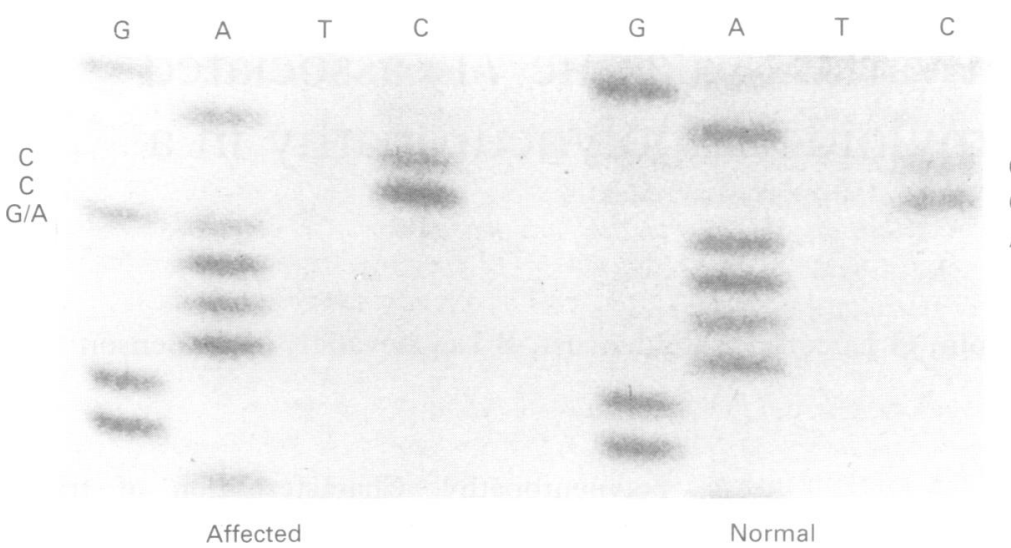

Figure 3 Autoradiograph of sequencing gel of exon 3 showing both ACC (threonine) and GCC (alanine) for positions corresponding to TTR codon 49 for an affected subject, but only ACC (threonine) for a normal subject.

analysis of plasma transthyretin. A new tryptic peptide was found on HPLC which had an alanine amino-terminus corresponding to position 49 of the TTR protein. Confirmation of this mutation was delayed until direct genomic DNA sequencing was accomplished.

DNA sequencing confirmed that an $A \rightarrow G$ mutation was present in the position corresponding to the first base of codon 49. This would give the alanine for threonine substitution in the mature protein. RFLP analysis using PCR-IMRA showed that four affected sibs in the kindred had this particular mutation. A cousin who was reported as affected in the original report of this kindred ${ }^{2}$ because she had paraesthesiae was found to be negative by PCR-IMRA. Clinical re-evaluation of this subject showed no progression of neuropathic symptoms over an eight year period and rectal and nerve biopsies were negative for amyloid.

The alanine for threonine substitution at position 49 has been reported by Salvi et $a l^{10}$ in

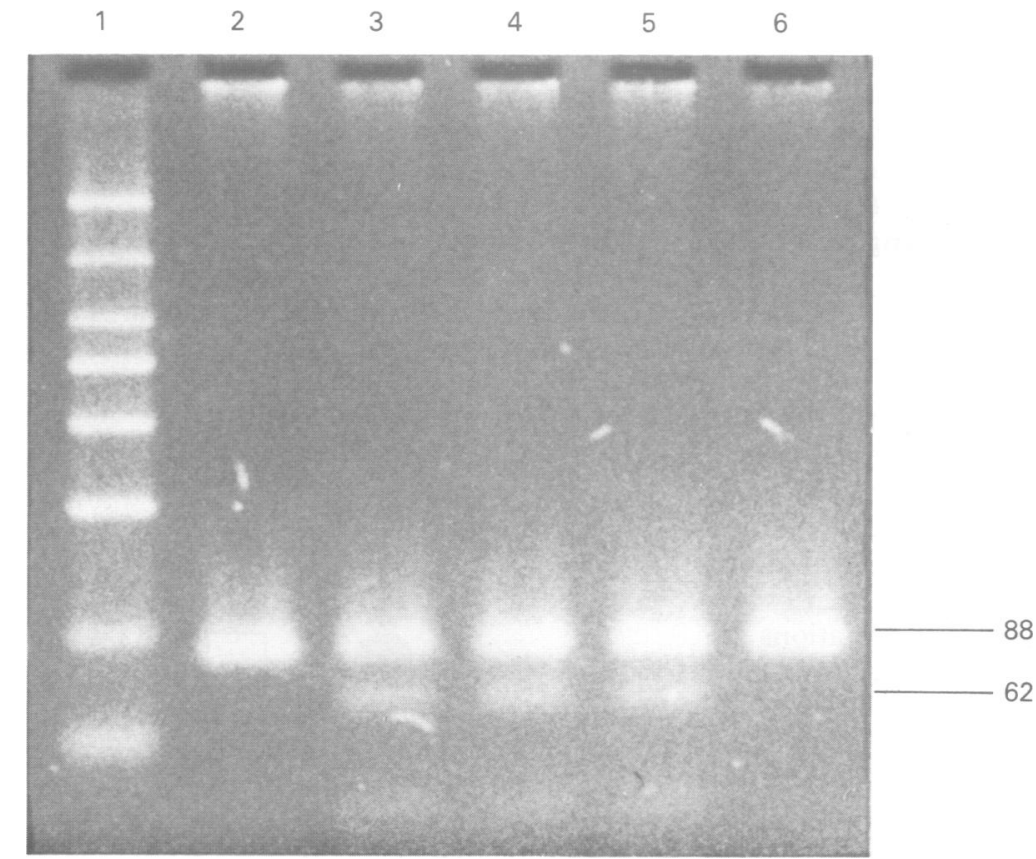

Figure 4 Ethidium stained 4\% agarose gel of Bgll digested PCR products. Lanes 3, 4 , and $5(I I I \cdot 1, I I I \cdot 4, I I I \cdot 6)$ show both the normal 88 bp product and a $62 \mathrm{bp}$ digestion product indicating heterozygosity for the Ala 49 TTR mutation. Lanes 2 and 6 show only the normal $88 \mathrm{bp}$ band (unaffected controls). Lane 1, markers (BioMarker Low, BioVentures, Inc). an Italian kindred. The clinical syndrome in that kindred was described as appearing between the ages of 40 and 48 . Vitreous deposits were the presenting symptom in the patients described, and this sets the syndrome apart from that seen in the French family described here. Cardiac involvement was described in each of the three subjects reported in the Italian kindred, but no mention was made of carpal tunnel syndrome which is the presenting feature in the French patients. PCR-IMRA was used in the present study to identify subjects with the $A \rightarrow G$ mutation in TTR. This is a rapid, non-isotopic method for screening and has proven to be reliable. Almeida et al $^{11}$ used allele specific oligonucleotide (ASO) probes to identify gene carriers in the Italian family, a method which requires radioactive labelling and attention to hybridisation conditions.

As pointed out by Julien et $a l^{2}$ FAP is relatively common in France. We have identified a family with cardiomyopathy in Amiens which is associated with the tyrosine 77 TTR mutation originally described in a German family from Illinois, USA. ${ }^{12}$ In addition, we have studied a family in Caen which has FAP associated with a different TTR mutation. Thorough characterisation of these amyloid associated mutations in TTR will be important in medical care and genetic counselling for the families involved.

This work was supported by Veterans Affairs Medical Research (MRIS 583-0888), and grants from RR-00750 (GCRC), United States Public Health Service, NIDDK-34881, NIDDK-42111, National Institute of Arthritis Metabolism and Digestive Diseases (AM20582), The Arthritis Foundation, and The Marion E Jacobson Fund.

1 Benson MD, Wallace MR. Amyloidosis. In: The metabolic basis of inherited disease. New York: McGraw-Hill, 1989;2439-60.

2 Julien J, Vital C, Vallat JM, Lagueny A, Ferrer X. Neuropathies amyloides familiales dans trois familles d'origine Française. Rev Neurol (Paris) 1983;139:259-67.

3 Benson MD, Dwulet FE. Prealbumin and retinol binding protein serum concentrations in the Indiana type hereditary amyloidosis. Arthritis Rheum 1983;26:1493-8.

4 Dwulet FE, Benson MD. Polymorphism of human plasma thyroxine binding prealbumin. Biochem Biophys Res thyroxine binding prealbum

5 Madisen L, Hoar DI, Holroyd CD, Crisp M, Hodes MD DNA banking: the effects of storage of blood and isolated DNA banking: the effects of storage of blood and isolated DNA on the inte

6 Nichols WC, Benson MD. Hereditary amyloidosis: detection of variant prealbumin genes by restriction enzyme analysis of amplified genomic DNA sequences. Clin Gene 1990;37:44-53.

7 Nichols WC, Liepnieks JJ, Benson MD, McKusick VA Direct sequencing of the gene for Maryland/German familial amyloidotic polyneuropathy type II and genotyping by allele-specific enzymatic amplification. Genomics 1989;5:535-40.

8 Haliassos A, Chomel JC, Tesson L, et al. Modification of enzymatically amplified DNA for the detection of point mutations. Nucleic Acids Res 1989;17:3606.

9 Rukavina JG, Block WD, Jackson CE, et al. Primary systemic amyloidosis. Medicine (Baltimore) 1956;35:239334.

10 Salvi F, Plasmati R, Michelucci R, et al. Clinical characterization of a new TTR variant in an Italian family: TTR zation of a new TTR variant in an Italian family: TTR
Ala 49. In: Amyloid and amyloidosis. Dordrecht: Kluwer Ala 49. In: Amyloid and amyloidosis.

11 Almeida MR, Gawinowicz M, Costa PP, et al. A new transthyretin variant associated with familial amyloidotic
theida polyneuropathy in an Italian kindred. In: Amyloid and amyloidosis. Dordrecht: Kluwer Academic Publishers, 1990:599-602.

12 Satier F, Nichols WC, Benson MD. Diagnosis of familial amyloidotic polyneuropathy in France. Clin Genet 1990;38:469-73. 